\title{
Affect on Alzheimer's Disease during Covid-19
}

\author{
Amisha Gupta - Student researcher of Biopsychology \\ Laureate certified Student Researcher | Davidson Young Scholar - \\ ( http://yspw.davidsongifted.org/yspw/users/amishagupta)| \\ Community \\ service ( http://peerknowledgesharing.com/amisha-gupta/) | NATS \\ $20211 s t$ \\ Place winner ( https://youtu.be/9H-Q0e2PCAw) | Youtube profile : \\ ( https://www.youtube.com/c/AmishaGuptaClassicalMusic) \\ LinkedIn : (h ttps://www.linkedin.com/in/amisha-gupta-3a6940201/) \\ | Cherry Creek High School - Colorado \\ email: guptaamishagupta@gmail.com
}

\begin{abstract}
The pandemic COVID-19 is generating worldwide disruption, straining health systems, causing morbidity and death, and placing people with ADRD in danger. In this article, we look at the present and anticipated implicationson people with ADRD as a result of the epidemic. We examine and offer reducing measures and death in peopleCOVID-19's effect on ADRD diagnosis and medical care in people with ADRD; and the COVID-19 repercussions of societal reactions in various ADRD care settings. COVID-19's influence on physicians and caregivers of people with ADRD; stigma, mental health, and trauma during COVID19; and the prospective COVID-19 impact research on ADRD.Despite much uncertainty, we may be able to avoid or lessen the suffering caused by the epidemic of COVID-19implications for persons with ADRD and about their careers.Anticipated the potential patterns of COVID-19 effects in the world dependent on data gathered from Kaggle and used the OptumLabs Data Warehouse (OLDW),
\end{abstract}

Keywords: COVID-19,Alzheimer's disease and related disorders(ADRD), Alzheimer's disease (AD), mild cognitive impairment (MCI), frontotemporal dementia (FTD), Lewy-body associated dementia (LBD), vascular dementia (VD).

\section{Introduction:}

In late 2019, a new Respiratory infections syndrome, coronavirus ( sars syndrome coronavirus 2 (SARS-CoV-2) was discovered. It has been determined that it is the source of COVID-19 is a respiratory ailment that can be mild or severe. On COVID-19 will affect 113 nations on January 01, 2021. COVID-19 has been declared a pandemic by the World Health Organization, with "alarming levels of infection." "Distribution and intensity."While the crisis is still developing, the pandemic has already wreaked havoc on the three-dimensional world in different ways: its physical health effects, its effects concerning the healthcare system, as well as the socioeconomic repercussions of the pandemic's action. People with ADRD have been among society's most vulnerableduring normal periods, relying on family or expert caretakers for daily survival.This pandemic exasperates their risk, due to both COVID-19-related illness and mortality, as well as the pandemic's indirect impact on the welfare support andthey rely on the healthcare system.Comprehension and awareness of the pandemic's present and prospective impact on individualscan assist in the care if they have ADRD. These would be the aspects to considerthat can also impact caregivers' judgmentsHealth care providers, organizations, and lawmakers are all involved.As a result, in the face of a quickly changing circumstance,This Special Article examines and suggests solutions to the problem.Six big concerns require six different strategies: 1)why people with ADRD are at such an elevated danger for COVID-19 and the mortality and death that comes with it; 2) how COVID-19 will affect ADRD diagnostic test and management of diseases; 3) the effect of example today to COVID-19 in various ADRD healthcare setting; 4) the impact of COVID-19 on caretakers and ADRD specialists patients; 5) trauma, psychological hygiene andin the COVID-19 era, a stigma exists.; and 6) how COVID-19's possible effects on ADRD researches threatens the patients of tomorrow. (We regard mild cognitive impairment $[\mathrm{MCI}]$ to be the least severe manifestation of ADRD in this Special Article.). 
Table.1. COVID-19 Factsheet for the World and the Top 6 Countries on January 22, 2021

\begin{tabular}{|l|l|l|l|}
\hline Country & Cases & Deaths & Transmission classification \\
\hline WORLD & $96,012,792$ & $2,075,870$ & \\
\hline United States & $24,225,155$ & 402,803 & Community transmission \\
\hline India & $10,625,428$ & 153,032 & Cluster of cases \\
\hline Brazil & $8,638,249$ & 212,831 & Community transmission \\
\hline Russia & $3,655,839$ & 67,832 & Cluster of cases \\
\hline UK & $3,505,758$ & 93,290 & Community transmission \\
\hline France & $2,916,577$ & 71,261 & Community \\
\hline
\end{tabular}

Table2 EpidemiologicaldefinitionsandCOVID-19factsheet comparing India vs global on January,22 2021

Definition

India Global

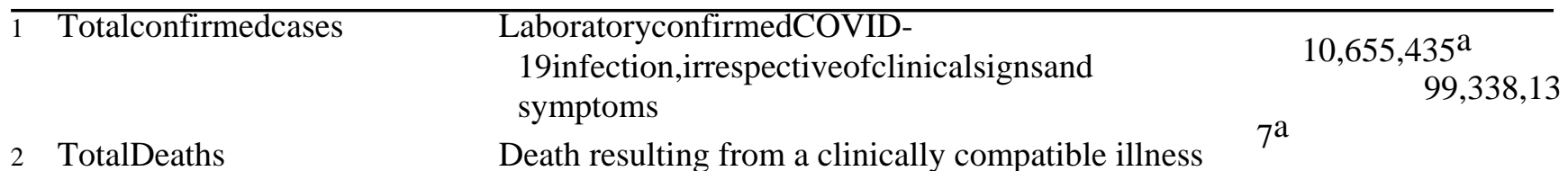
in a probable orconfirmedCOVID-

19 case, unlessthereisaclearalternativecauseofdeath $\quad 153,376^{\mathrm{a}}$ that cannotbe related toCOVID-19 disease

3 Recoveredcases $10,316,786^{\mathrm{a}}$

4 Activecases $25,816,876^{\mathrm{a}}$

5 ConfirmedcasespermillionpopulationTotalnumber ofcasesordeathsdividedby thetotalpopulationof

thecountryorcumulativetotalofconfirmedcases permillionofallcountry for world

$71,390,635^{\mathrm{a}}$

Activecases=totalcases $-($ totaldeaths + Recoveredcases) $185,273 *$
6

7 CaseFatality Rate NA

8 RecoveryRate

9 Totaltestsdone

10 Testsdonepermillionpopulation Totaltestsdone

Cumulativetotalsamplestested(whichincludesb othRTPCRandRAT) up to January 23,2021

Totalpopulation ofthe country

11 Positivityrate

12 InfectionFatalityRatio(IFR)

Proportion of deathsamong allinfected individuals

Totalpopulationofthecountry/world

Totalnumberofrecoveredc asesX100Totalconfirmed cases Totalnumberoftestspositive

Totalnumberof testsdone ataparticular time $7679^{\mathrm{a}} \quad 12,744^{\mathrm{a}}$

$111^{*} \quad 273.3^{*}$

Itis aratio of totaldeaths andconfirmed casesat onepoint of time $1.4 \%{ }^{\wedge}$ $96.78 \%^{\mathrm{b}} \quad \mathrm{NA}$

$19,17,66,871^{\mathrm{a} N A}$

NA : Not Available 


\subsection{COVID-19 and its Related Mortality and Morbidity are a Major Risk for People with ADRD.}

Various characteristics of ADRD may enhance the likelihood of COVID-19 infection. Personal hygiene, concealing one's nose and mouth when coughing, keep an eye out for and identifying COVID-19 Symptoms, physical well-being separation other people, and by staying at home alone, you may keep your individualityare all advice given by public health officials to limit COVID-19 transmission. 2 Due to apathy or depression, some people with MCI or mild forms of dementia may be unwilling or being unable to comply.Because of thedegree as a result of their short-term memory impairment and overall memory deficits, someone with more severe forms of dementia will be unable to recognize, appreciate, or remember the majority of this advice. Finally, behavioral and psychological symptoms of dementia (BPSD), like motor anxiety, invasiveness, and roaming, can jeopardize isolation efforts.Despite concerns and inconsistency in COVID-19 outcome estimations, age and concomitant medical disorders have continuously been the most important considerations linked to a bad prognosis, including hospitalization and death. The best documentedADRD is a risk factor, symptoms and severe disease, and COVID death is age- 21.7 years. This is shown by the scenario nearly a third of the cases are recorded in Italy and nearly nine out of ten deaths occur in people aged 65 and up. 3 Accurate estimation of results will only become available over time, but they appear to be influenced by local factors like demography and resources, particularly the healthcare system's capacity to adapt.Because of the link of ADRD in combination with physical activity comorbidities and other symptoms of ADRD,patients with ADRD are likely to have a higher rate of morbidity. When compared to people of the same age who do not have dementia, those with Alzheimer's disease seem to be more likely to suffer from cardiovascular disease events, diabetes, and pneumonia. 5 In people with COVID-19.6, several factors have been linked to lower results, involving death. In China, pneumonia was found in nearly $90 \%$ of theCOVID-19 has been confirmed in 1,085 patients. 7 In the absence of the epidemic, pneumonia mortality has been estimated to be two times higher in people with dementia as it is in people without dementia.

\section{The Diagnose and Medical Management of ADRD Will Be Affected by COVID-19}

The dramatic rise in COVID-19 cases is wreaking havoc on healthcare systems, generating a lack of a number of hospital beds putting a strain on healthcare workers9 Health care systems may face greater demandcause resources to be diverted away from chronically ill patients, such as ADRD.Optional and non-urgent care is being suspended in several of the areas affected. When the number COVID-19 cases that are severe outnumbers community resources, the accessibility of urgent and intensive care resource base is jeopardized. 10 Because of the fact that their sickness is persistent and that they haven't been able to find a cure for unique care demands, people with ADRD may be disproportionately affected by resource constraints.

\subsection{Diagnosis, Workup, ADRD Monitoring and Clinical Follow-up:}

The physical examination, as well as ADRD diagnosis,might be hampered in a variety of ways. Due to the redeployment of primary care clinicians and specialized to manage emergency situations, these doctors are unable to work up neuropsychological issues. Attending one or more appointments at a clinic, including blood tests and neuronimaging, exposes vulnerable people to risks that may outweigh the advantages of timely monitoring and evaluation.Outpatient physicians have converted to delivering virtually care in many countries, conducting exams and follow-ups over the phone or by videoconferencing. These technologies may not be sufficient for performing various neurological examinations, as well as some intelligence tests, which are necessary fordetermining whether you have MCI or dementia, as well as keeping track of it progression.In some circumstances, a personal first visit and followups through the internet may be possible. Otherwise, treatment and diagnosis may have to be postponed or limited.

\subsection{ADRD Medication Administration:}

Ant cholinergic antidepressants and meantime are commonly used in ADRD patients. Antipsychotic, antiepileptic ,antidepressant and other psychotropic drugs are widely used in the treatment of BPSD. 11 Patients who are on a consistent treatment plan may be affected if their medicine delivery is disturbed owing to missed appointments, Pickup or delivery from the pharmacy issues,Possible problems with the supply chain. When normal screening is disturbed, like in clinical examinations, blood tests, or an echocardiogram, or the capacityto keep track of negative events in a timely way, starting a new medicine when the epidemic could be linked with a greater incidence. If access to urgent care is hampered, serious adverse effects linked with meditation sessions used to treat ADRD and BPSD, such as bradycardia, gastrointestinal problems, fractures,falls, cardiovascular problems, or strokes are all possible causes of death, entail aincreased mortality and morbidity.Individual people with ADRD who are reliant on families or health care professionals for medication reminder or help are at risk of abrupt medication discontinuance when they are socially isolated. If proper prescribing and monitoring are not possible, the overall risk of several dementia drugs may move toward damage. 


\subsection{No Pharmaceutical Treatment: \\ 23.1 Contact with others, both socially and physically:}

likePet therapy, social clubs, and exercise groups, are common no pharmacologic therapies for ADRD in general and BPSD in particular in specific. Due to a shortage of resources and the requirement for physical separation,these interventions will be halted, resulting in greater Isolation and a lack of physical activity, diminished social interaction, and a halt toIsolation and a lack of physical activity. Many individuals nowadays rely on technology to socialize and even exercisegroups while restricted at home; however, those it's possible that people with ADRD won't be able to use electronic tools or software (see below).

\subsubsection{After the Pandemic, Medical Assistance:}

The end of the pandemic may be linked to an increase in demand for previously postponed care. Those with ADRD and their families may also require aid in resuming treatment and addressing difficulties that resulted from a lack of follow-up and oversight, as well as a halt in therapies that are beneficial to one's health.

\section{The Effects of COVID-19 and societal responses in ADRD care settings}

Restricted travel and confinement at home ("lockdowns") are part of the public's reaction to the epidemic. People are urged or forced to segregate themselves socially and stay at home. Businesses that aren't absolutely necessary are shut down. The scope and length These social segregation measures are unknown, but in some jurisdictions, they may be severe and long-lasting. Many resources that patients with ADRD rely on may become inaccessible in this situation.People with ADRD live in a variety of contexts and depend on the accessibility and availability of different resources, depending on how serious their sickness. These factors may have an impact on both the risk and the societal impact of COVID-19 implications in the COVID-19 pandemic's context.

\subsection{Community:}

The majority of people having a milder form of ADRD require little take care of yourself and live in their communities may have built up a strong base of support. Therefore, It's possible that their ability to survive in the neighborhood will be jeopardized. if it is reliant on services that are interrupted as a result of the flu pandemic Meals on Wheels and other delivery services Due to excessive traffic, wheels may be postponed or disrupted. Requests, closures, or supply chain breakdowns are all possibilities.Family or professional carers may be necessary due to increased demand, workers' illness, or mandatory separation due to exposure(e.g.Workers in the field of home health care) to provide in-home assistance for regular living activities could be inaccessible; Some employees could also be prohibited from their employer trying to workin various contexts. Individuals suffering from ADRD who live in the it might be a community especially susceptible if they can't find what they're looking for medical treatment if they become sick. COVID-19 has been linked to a rapid decrease in respiratory function as well as heart problems. As a result, symptomatic while some people require focused, others do not. keeping a safe range.Many people ADRD patients who need on individual Savings and investments are at an all-time highvulnerable to economic hardship as a result of the pandemic's economic impacts. They, like other people, may require financial assistance from the government.Those really aremuch less likely to operate a vehicle private machine, preferring otherwise to rely on public transport or other modes of mobility, which increases their exposures and the possibility of disease. They could gain from ithelp locating safe modes of transportation and limiting their need to leave the house with expediting delaying and delivering unnecessary trips.As a result of greater separation and group disintegration, activity, persons who live if you're alone in the neighborhood, it's possible that you'll experience loneliness. Alternate social and physical activities must be incorporated into the household in a safe manner. While many people use technologies to remain inextricably connected and able to take advantage of services such as some health care persons with ADRD, it's possible find it difficult to use technology owing to cognitive impairment. They may require training and assistance in order to use these instruments.Individuals with ADRD and their families, like anybody else, must prepare for a disaster.vital services provision Families' and careers' perspectivesa sense of the dangers and disruptions that could occurPatients with ADRD who live in the community should follow the guidelines outlined above.In the community, they may be able to lessen their effect.Increase insupport is one possible mitigation strategy more in the form of frequently telephonecontact information or a video chat, and difficulty to keep things running smoothlydelivery of caregivers' services, as well as future planningshifting to a new place or causing a disruptionwhere the necessary assistance can be offered.Surprisingly, since they are unable to attend work to lockdowns or other limitations, certain families might be able to helptemporary assistance at home in community figure 1 . 

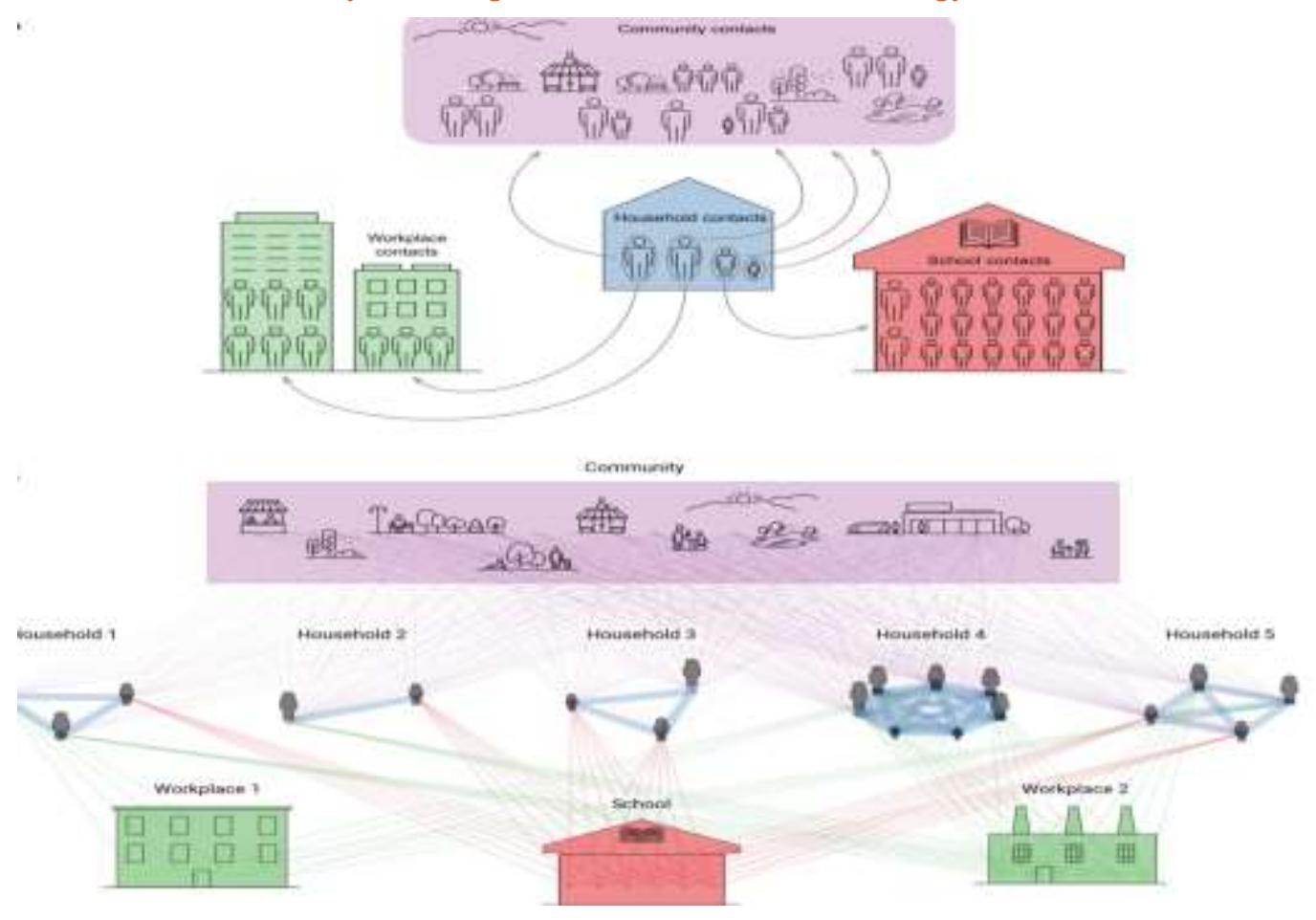

Figure 1. Community Spread COVID-19

\subsection{Assisted and Group Living:}

Many of the challenges that people with ADRD confront in the society also affect those who live in group and assisted living settings. If returning home is a possibility, the higher the possibility of illness in relation to big gatherings can alter the a risk-benefit analysis in favor of return home. However, because of their reduced level of functioning, many people ADRD necessitates a supported living conditions. Physical contact and toileting, congestion and sharing rooms as well as employees doing work in different it is possible to change the parameters all enhance in these settings. As previously mentioned, characteristicsof mild dementia, such as severe memory loss, and BPSD, Wander and anxiety, for example, may occur impede efforts in order to promote suggested activities to lessen transmission risk.Imposing stricter hand hygiene, seclusion, or restrictions on visitors and activities, on the other hand, may exacerbateBPSD or cognitive deficits, resulting in increased care demands and dangers.

\subsection{Hospital:}

Patients with ADRD suffer from a variety of symptomsadmitted to hospitals for BPSD, concomitant disease, or inability to care for oneself owing to a lack of supportive resources or long-term care. 15 Hospitals have the same hazards as LTC, but they also have added dangers. Hospitals employees as well as doctors particularly susceptible to infection. COVID-19: 1,716 (3.7 percent) of China's the first 4,9456 cases that have been confirmed (as of march 15, 2020) there were 2,026 health care workers and experts in total( 10.0 percent) of Italy's 30,123confirmed cases in the beginning (as of april 15, 2020). Patient turnover is significant due to high staff ratios and turnoverloads, packed rooms, quick detectable influx and undiscovered COVID-19 cases, and a limited the risk of COVID-19 nosocomial infection is reduced when PPE is availableconsiderable. Individuals with ADRD are among the most vulnerable to nosocomial infection for the reasons mentioned above (age, co morbidities, behavioral, and cognitive issues).Hospitals are pressured or overburdened in many places affected by COVID-19. 9 Individuals with ADRD who are hospitalized may be especially vulnerable since they are unable to supervise their owntaking care of or advocating for themselves. In dementia, shorter nursing shifts have been linked to more medical errors and adverse occurrences. The fact that you need to be admitted to the hospital indicates that you have a more serious sickness. Patients with a severe case of BPSD may be at riskanfar greater danger of the preceding-mentioned behaviors that increase infection transmission. During a COVID19 outbreak on a psych facility in Seoul unit, infection was found in 102 of 109 inpatients, with seven of them dying. In this case, of possible, confirmed or probable instances of COVID-19, hospitals must assess the danger to people suffering with ADRD as well as other people's safety upon admission. The requirement regarding locking systems and their use isolation, In high-risk cases, pharmacological and physical restraints, as well as end-of- 
life or palliative care, may be used necessitates planning to define ethical issues problems, the legal structure and institutional arrangements that impact a choice on a local level. In certain pandemic-affected jurisdictions, health care treatments that are taken for sure could be restricted, regardless of the decisions created by ADRD sufferers or their relatives (see below).

\section{COVID-19's Impact on ADRD Patients' Caregivers and Physicians:}

Because the majority of ADRD patients rely on careers, the pandemic's influence on professional and informal caregivers must be recognized. Some caregivers' physical and mental health is perilous even in the best of times. Some caregivers may become unwell, need to isolate and be inaccessible during the pandemic, or suffer panic and other psychological issues difficulties. As previously stated, members of the family may be forced to develop into caretakers for a relation suffering from ADRD as a result of the unexpected absence Among well-known services. Parentscaregivers who have lost a loved one are prone to experience grief and its repercussions.one, as well as in professional caregivers who have experienced the loss of a patient. All of the aforementioned factors will result in tiredness and burnout. As previously stated, certain different parts of care for people physical exercise is associated with ADRDseparation. Insufficient personal protective equipment (Personal Protective Equipment) or instruction on how to utilize itestablishes the conditions for viral propagation.In most cases, in response to dissent and violent threats necessitates quick remedies, which obstruct correct PPE usage and raise the danger of virus exposure.All physicians may be called upon to address a variety of medical problems that would normally be handled by professionals. Patients and families are involved in pre-planning discussions required such as establish the aims of these should be handled with cautionsevere conditions happen; it really are especially important if there is an advanced code condition discussions have not previously occur or do not occur properly publicized.Health-care employees who provide care for people with ADRD are already vulnerable to pain and death.14 The immediate threat to their personal safety may exacerbate their tension and anxiety. COVID-19 has already surpassed the number of cases, the number of deaths, and the societal harm seen during the SARS pandemic in 2003. We must be ready to deal with mental health issues that are substantial and long-term repercussions of COVID-19 on health-care personnel, such asDepression and post-traumatic stress disorder, just as we were after SARS.

\section{In the Time of COVID-19, Mental Hygiene, Trauma, and Stigma:}

The COVID-19 pandemic has the possibility to disrupt not just ADRD patients' active care, however,theirschedules that improve mental well-being at a basic level.Fear, worry, and fury may arise as a result of the epidemic and its social effects. They are likely to disrupt all sorts of social connection for an extended length of time. Loneliness and unhappiness can be exacerbated by a lack of physical intimacy. Exercise is suggested for people with ADRD in general and in particular, as well as prison limitsaccessibility to physical activity.Sleep difficulties are prevalent in ADRD, and Anxiety and the loss of social habits are two of the most common symptoms of depression. ("zeitgeists") can further impair sleep.In turn, in people with ADRD, a lack of activity, a lack of sleep, and a lack of stimulation can lead to delirium, which increases morbidity and death.Individuals with ADRD, like health-care employees, may lose friends and relatives as a result of COVID-19. These losses might cause grieving, bereavement, or open depression, which is a prevalent symptom of ADRD. The epidemic and its aftermath may be viewed as a traumatic event, leading to posttraumatic stress disorder. Stress and trauma, on the other hand, can hasten cognitive impairment.Risk factors include age, disease, depression, trauma, and dementia for the purpose of suicide .Individuals with ADRD were affected by the epidemic.It's possible that you'll be stigmatized twice. Stigma is already a problem.ADRD has a widespread problem. Individuals who have, or are at risk of having,COVID-19 has been stigmatized due of the risk of exposure. Stigma can lead to sterilization and discrimination.denial of medical and social services, which happens as a result ofat a time when there may be a scarcity of resources to devoteBeyond some triage difficulties, rationing raises others.of the logistical concerns mentioned previously.Will older people with moderate ADRD be able to get into intensive care? Will they be removed off a ventilator if they are already on one to free up resources for younger patients? How will these choices be made in an ethical manner? What psychological effects would triage have on medical personnel?The scope of this study does not allow for a response to these difficult problems. However, in the unprecedented circumstances of the COVID-19 epidemic, several ethicists have offered a framework to address these difficulties.

\section{COVID-19's ADRD Research Impact Endangers Future Patients:}

The preceding debate has solely focused on the effects of the COVID-19 epidemic immediate risks and the ramifications people with ADRD, i.e. today's patients. Patients with ADRD, i.e. today's patients, are facing a 
pandemic. In addition, the pandemic poses a hazard to the environment."Tomorrow's patients" Several studies have already been conducted sounded the warning about how the COVID-19 epidemic was spreading Clinical research could be impacted in a way that has never been seen before. ways. The ramifications could be far worse. investigation into ADRD In the last two decades, the quantity of people using the internet has risen dramatically. people who One of the most active fields of research is ADRD drawing considerable funding for both basic and clinical research funding from the private sector, the government, and philanthropy world of Western.As of April 31, 2020, a clinicaltrials.gov search using the termsthe terms "dementia" or "dementia" yielded no results.

There are 592 active studies on "Alzheimer's illness." A

A recent investigation of the same registry, published in the same journal, discovered

There are 201 trials (including 53 phase 4 trials) looking into

There are 145 medicines for the therapy of ADRD, as well as another forthe treatment of other diseases different devices were put through their paces. a sudden stoppage of .All of these studies have been conducted would threaten not just a community has already taken a decision. a significant investment, however, it is possible that this will have a long-term impactimplications as for purpose of studies on ADRD.At the same time, the COVID-19 epidemic may be a blessing in disguise.stimulus for accelerating the adoption of novel clinical research design and methodology, substantially altering how ADRD trial participants are chosen and evaluated. The remainder this section's looks at whether and how clinical research should be conducted on ADRD can proceed throughout the epidemic.

\subsection{The COVID-19 Pandemic's Long-Term Impact on ADRD Research Methods}

The COVID-19 pandemic, like every big catastrophe, will own a long-term influence on howany clinical studies, particularly The study of ADRD is conducted.Researchers are being forced to consider how researchers could do the majority of their study operations remotely due to the current difficult scenario. It will hasten the adoption of technology and methods that allow for remote evaluations.In the realm of we are conducting ADRD researchexpect it will have the greatest influence on conventional neuropsychological and function evaluations account for the majority of main outcomes in ADRD intervention trials. These technical advancements will aid ADRD research in the long run since they ought to allow for the recruiting and supervision of considerably bigger sample are available at lower costs.Eventually, the COVID-19 situation may have a positive outcomehasten non-pharmaceutical therapies that can be given at the participants' homes, such as mental training or physical activity at home, or make use ofSmaller, portable gadgets for usage in residential residences, such as transcranial Devices that use current stimulation and others.Using diagnosis codes and anti-dementia drug fills, we found cases of ADRD that occurred between 2019 and 2021 in the OptumLabs Database. We created a categorization algorithm that took into account the time sequencing of diagnoses and the type of provider.

\subsection{RESULTS:}

We discovered 36,838 people with ADRD. Following the application of our approach, the most common cause of dementia was non-specific dementia $(41.2 \%)$, followed by people taking anti-dementia medication but not having an ADRD diagnosis (15.6 percent ). Alzheimer's disease patients made up 10.2 percent of the cases. The people who had vascular dementia had the most concomitant diseases. Dementia was initially documented predominantly in the office context (35.1 percent) indicate figure 2. 


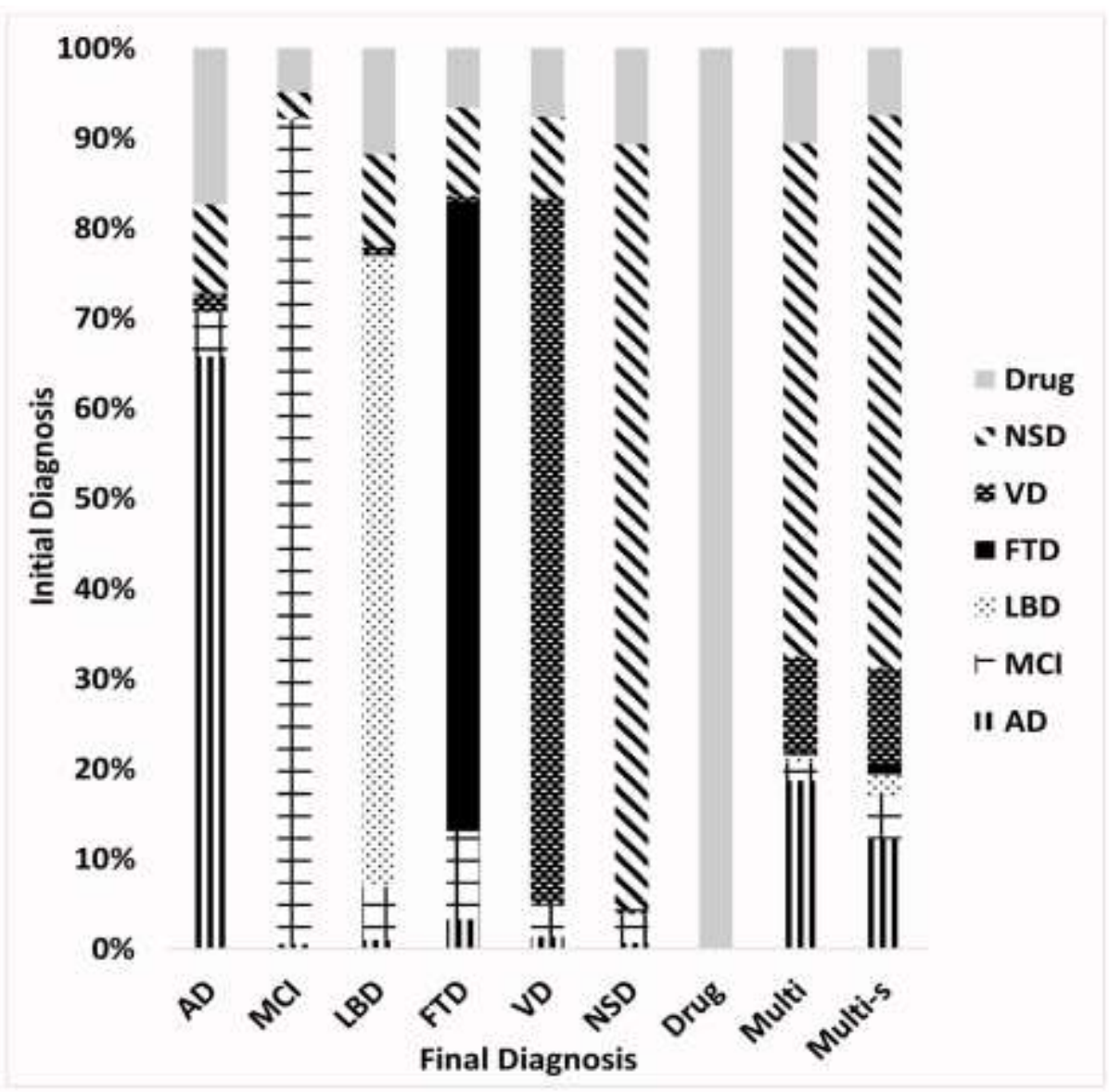

Figure 2: Initial Diagnosis Categorization into Alzheimer's Disease and Related Dementia Subtypes, $\mathrm{n}=36,838$

Note. $(n=3,748$;) Alzheimer's disease Mild cognitive impairment $(n=5,648)$; Lewy-body dementia $(n=204)$; Fronto-temporal dementia $(n=153)$; Vascular dementia $(n=1,520)$; Non-specific dementia $(n=15,166)$; Drug-only dementia $(n=5,736)$; Multiple dementia diagnoses by non-specialists $(n=3,147)$; Multiple dementia diagnoses by specialists $(n=1,516)$; other - this category combines two or more other subtypes when cell sizes were too small

\section{CONCLUSIONS:}

The COVID-19 epidemic is causing enormous disruptions in the world's health-care systems. This epidemic also jeopardizes the togetherness and future sustainability of ADRD research. based on specific circumstances Local effect will vary and evolve such as COVID-19 occurrence of social adjustments, resource availability, related mortality rates and adopted to contain the pandemic. Because of these geographical differences, as well as the variety of ADRD, simple generic advice are ineffective. However, understanding of this potential impact, as well as mitigation methods tailored may vary according to individual and local factorshelp to prevent or mitigate the suffering caused by this pandemic. However, knowledge of this potential impact, as well as mitigation methods tailored depending on the circumstances of the individual and the location, help to minimize or mitigate the suffering caused by this epidemic and its consequences implications for people with ADRD and their symptoms careers.

\section{References:}

1. Prince, M.; Ali, G.-C.; Guerchet, M.; Prina, A.M.; Albanese, E.;Wu, Y.-T. Recent global trends in the prevalence and incidence of dementia, and survival with dementia. Alzheimer's Res. Ther. 2016, 8, 23. [CrossRef]

2. Lane, C.A.; Hardy, J.; Schott, J.M. Alzheimer's disease. Eur. J. Neurol. 2018, 25, 59-70. [CrossRef] [PubMed]

3. Cahill, S. WHO's global action plan on the public health response to dementia: Some challenges and opportunities. Aging Ment. Health 2020, 24, 197-199. [CrossRef] [PubMed]

4. Prince, M.J.;Wimo, A.; Guerchet, M.M.; Ali, G.C.;Wu, Y.-T.; Prina, M. World Alzheimer Report 2015: The Global Impact of Dementia: An Analysis of Prevalence, Incidence, Cost and Trends; Alzheimer's Disease International: London, UK, 2015.

5. Jack, C.R.J.; Bennett, D.A.; Blennow, K.; Carrillo, M.C.; Dunn, B.; Haeberlein, S.B.; Holtzman, D.M.; Jagust,W.;

Jessen, F.; Karlawish, J.; et al. NIA-AA Research framework: Toward a biological definition of Alzheimer's disease. Alzheimers Dement. 2018, 14, 535-562. [CrossRef] [PubMed]

6. Petersen, R.C. Mild cognitive impairment as a diagnostic entity. J. Intern. Med. 2004, 256, 183-194. [CrossRef] 
7. Butterfield, D.A.; Perluigi, M.; Sultana, R. Oxidative stress in Alzheimer's disease brain: New insights from redox proteomics. Eur. J. Pharmacol. 2006, 545, 39-50. [CrossRef]

8. Swomley, A.M.; Forster, S.; Keeney, J.T.; Triplett, J.; Zhang, Z.; Sultana, R.; Butterfield, D.A. Abeta, oxidative stress in Alzheimer disease: Evidence based on proteomics studies. Biochim. Biophys. Acta 2014, 1842,1248-1257. [CrossRef]

9. Racchi, M.; Uberti, D.; Govoni, S.; Memo, M.; Lanni, C.; Vasto, S.; Candore, G.; Caruso, C.; Romeo, L.;Scapagnini, G. Alzheimer's disease: New diagnostic and therapeutic tools. Immun. Ageing 2008, 5, 7.[CrossRef]

10. Perez Ortiz, J.M.; Swerdlow, R.H. Mitochondrial dysfunction in Alzheimer's disease: Role in pathogenesis and novel therapeutic opportunities. Br. J. Pharmacol. 2019, 176, 3489-3507. [CrossRef]

11. Tramutola, A.; Lanzillotta, C.; Perluigi, M.; Butterfield, D.A. Oxidative stress, protein modification and Alzheimer disease. Brain Res. Bull. 2017, 133, 88-96. [CrossRef]

12. Harris, S.A.; Harris, E.A. Herpes simplex virus type 1 and other pathogens are key causative factors in sporadic Alzheimer's disease. J. Alzheimer's Dis. 2015, 48, 319-353. [CrossRef] [PubMed]

13. Itzhaki, R.F. Corroboration of a major role for herpes simplex virus type 1 in Alzheimer's disease.Front. Aging Neurosci. 2018, 10, 324. [CrossRef] [PubMed]

14. Itzhaki, R.F.; Lin,W.R.; Shang, D.;Wilcock, G.K.; Faragher, B.; Jamieson, G.A. Herpes simplex virus type 1 in brain and risk of Alzheimer's disease. Lancet 1997, 349, 241-244. [CrossRef]

15. Montagne, A.; Nation, D.A.; Sagare, A.P.; Barisano, G.; Sweeney, M.D.; Chakhoyan, A.; Pachicano, M.; Joe, E.;Nelson, A.R.; D'Orazio, L.M.; et al. APOE4 leads to blood-brain barrier dysfunction predicting cognitive decline. Nature 2020, 581, 71-76. [CrossRef]

16. Wozniak, M.A.; Itzhaki, R.F. Antiviral agents in Alzheimer's disease: Hope for the future? Ther. Adv. Neurol. Disord. 2010, 3, 141-152. [CrossRef]

17. Jeong, H.-H.; Liu, Z. Are HHV-6A and HHV-7 really more abundant in Alzheimer's disease? Neuron 2019,104, 1034-1035. [CrossRef]

18. van den Pol, A.N. Viral infection leading to brain dysfunction: More prevalent than appreciated? Neuron 2009, 64, 17-20. [CrossRef]

19. Kucharski, A.J.; Russell, T.W.; Diamond, C.; Liu, Y.; Edmunds, J.; Funk, S.; Eggo, R.M. Early dynamics of transmission and control of COVID-19: A mathematical modelling study. medRxiv 2020. [CrossRef]

20. Chang, M.C.; Baek, J.H.; Park, D. Lessons from South Korea regarding the early stage of the COVID-19 outbreak. Healthcare 2020, 8, 229. [CrossRef] Healthcare 2020, 8, 2867 of 10

21. Mao, L.; Jin, H.; Wang, M.; Hu, Y.; Chen, S.; He, Q.; Chang, J.; Hong, C.; Zhou, Y.; Wang, D.; et al. Neurologic manifestations of hospitalized patients with coronavirus disease 2019 in Wuhan, China. JAMA Neurol. 2020. [CrossRef]

22. Ellul, M.A.; Benjamin, L.; Singh, B.; Lant, S.; Michael, B.D.; Easton, A.; Kneen, R.; Defres, S.; Sejvar, J.; Solomon, T. Neurological associations of COVID-19. Lancet Neurol. 2020. [CrossRef]

23. Heneka, M.T.; Golenbock, D.; Latz, E.; Morgan, D.; Brown, R. Immediate and long-term consequences of COVID-19 infections for the development of neurological disease. Alzheimer's Res. Ther. 2020, 12, 69. [CrossRef] [PubMed]

24. Benussi, A.; Pilotto, A.; Premi, E.; Libri, I.; Giunta, M.; Agosti, C.; Alberici, A.; Baldelli, E.; Benini, M.;Bonacina, S.; et al. Clinical characteristics and outcomes of inpatients with neurologic disease and COVID-19 in Brescia, Lombardy, Italy. Neurology 2020. [CrossRef] [PubMed]

25. Fotuhi, M.; Mian, A.; Meysami, S.; Raji, C.A. Neurobiology of COVID-19. J. Alzheimer's Dis. 2020, 76, 3-19.[CrossRef]

26. Yan, R.; Zhang, Y.; Li, Y.; Xia, L.; Guo, Y.; Zhou, Q. Structural basis for the recognition of SARS-CoV-2 by full-length human ACE2. Science 2020, 367, 1444-1448. [CrossRef]

27. Donoghue, M.; Hsieh, F.; Baronas, E.; Godbout, K.; Gosselin, M.; Stagliano, N.; Donovan, M.; Woolf, B.; Robison, K.; Jeyaseelan, R.; et al. A novel angiotensin-converting enzyme-related carboxypeptidase (ACE2) converts angiotensin I to angiotensin 1-9. Circ. Res. 2000, 87, E1-E9. [CrossRef]

28. Hamming, I.; Timens, W.; Bulthuis, M.L.C.; Lely, A.T.; Navis, G.J.; van Goor, H. Tissue distribution of ACE2 protein, the functional receptor for SARS coronavirus. A first step in understanding SARS pathogenesis. J. Pathol. 2004, 203, 631-637. [CrossRef]

29. Matsuda, K.; Park, C.H.; Sunden, Y.; Kimura, T.; Ochiai, K.; Kida, H.; Umemura, T. The vagus nerve is one route of transneural invasion for intranasally inoculated influenza a virus in mice. Vet. Pathol. 2004, 41,101-107. [CrossRef]

30. Li, Y.-C.; Bai,W.-Z.; Hirano, N.; Hayashida, T.; Hashikawa, T. Coronavirus infection of rat dorsal root ganglia: Ultrastructural characterization of viral replication, transfer, and the early response of satellite cells. Virus Res. 2012, 163, 628-635. [CrossRef]

31. Li, Y.-C.; Bai, W.-Z.; Hirano, N.; Hayashida, T.; Taniguchi, T.; Sugita, Y.; Tohyama, K.; Hashikawa, T. Neurotropic virus tracing suggests a membranous-coating-mediated mechanism for transsynaptic communication. J. Comp. Neurol. 2013, 521, 203-212. [CrossRef]

32. Netland, J.; Meyerholz, D.K.; Moore, S.; Cassell, M.; Perlman, S. Severe acute respiratory syndrome coronavirus infection causes neuronal death in the absence of encephalitis in mice transgenic for human ACE2. J. Virol. 2008, 82, 7264-7275. [CrossRef] [PubMed]

33. Li, K.; Wohlford-Lenane, C.; Perlman, S.; Zhao, J.; Jewell, A.K.; Reznikov, L.R.; Gibson-Corley, K.N.; Meyerholz, D.K.; McCray, P.B.J. Middle East respiratory syndrome coronavirus causes multiple organ damage and lethal disease in mice transgenic for human dipeptidyl peptidase 4. J. Infect. Dis. 2016, 213, 712-722. [CrossRef] [PubMed]

34. Lechien, J.R.; Chiesa-Estomba, C.M.; De Siati, D.R.; Horoi, M.; Le Bon, S.D.; Rodriguez, A.; Dequanter, D.;Blecic, S.; El Afia, F.; Distinguin, L.; et al. Olfactory and gustatory dysfunctions as a clinical presentation of mild-to-moderate forms of the coronavirus disease (COVID-19): A multicenter European study. Eur. Arch. Oto-Rhino-Laryngol. 2020, 277, 2251-2261. [CrossRef] [PubMed]35. To, K.F.; Lo, A.W.I. Exploring the pathogenesis of severe acute respiratory syndrome (SARS): The tissue distribution of the coronavirus (SARS$\mathrm{CoV}$ ) and its putative receptor, angiotensin-converting enzyme 2 (ACE2). J. Pathol. 2004, 203, 740-743. [CrossRef] [PubMed]

36. Liao, M.; Liu, Y.; Yuan, J.; Wen, Y.; Xu, G.; Zhao, J.; Cheng, L.; Li, J.; Wang, X.; Wang, F.; et al. Single-cell landscape of bronchoalveolar immune cells in patients with COVID-19. Nat. Med. 2020, 26, 842-844. [CrossRef]

37. Sungnak,W.; Huang, N.; Bécavin, C.; Berg, M.; Queen, R.; Litvinukova, M.; Talavera-López, C.; Maatz, H.;Reichart, D.; Sampaziotis, F.; et al. SARS-CoV-2 entry factors are highly expressed in nasal epithelial cells together with innate immune genes. Nat. Med. 2020, 26, 681-687. [CrossRef] 